\title{
RELAÇÕES ENTRE A PRÁTICA DE ATIVIDADES FÍSICAS E ESPORTIVAS ESCOLARES E EXTRAESCOLARES DE ALUNOS DO ENSINO MÉDIO
}

\author{
Diego Busin, Universidade de Caxias do Sul - UCS, Caxias do Sul, Rio Grande do Sul- \\ Brasil \\ Daniel Marcon, Universidade de Caxias do Sul-UCS, Caxias do Sul, Rio Grande do Sul \\ - Brasil
}

\begin{abstract}
RESUMO
A literatura demonstra que muitos alunos do Ensino Médio não sentem motivação para participar das aulas de Educação Física. Diante disso, este estudo buscou analisar as razões que levam alguns alunos a praticar atividades físicas e esportivas fora da escola, apesar de não terem motivação nas aulas de Educação Física na escola. Caracterizado como um estudo de caso qualitativo, de cunho descritivo, participaram sete alunas do Ensino Médio de uma escola privada do interior do Rio Grande do Sul. Os critérios de inclusão foram: número elevado de falta às aulas; confirmação da pouca motivação para participar das aulas de Educação Física; e praticar atividades físicas e esportivas extraescolares. Os dados foram coletados por meio de entrevista semiestruturada. Os resultados demonstraram que as alunas procuram fora da escola atividades físicas e modalidades esportivas que lhes tragam prazer, satisfação pessoal e aprendizado que, apesar de procurar, não encontram nas aulas de Educação Física escolar.
\end{abstract}

Palavras-Chave: Educação Física escolar; Ensino médio; Motivação; Atividades físicas e esportivas.

\section{RELATIONS BETWEEN PRACTICAL OF PHYSICAL AND SPORTING ACTIVITIES TO SCHOOL AND OUTSIDE OF SCHOOL OF STUDENTS HIGH SCHOOL}

\begin{abstract}
Literature shows that many High School students do not feel motivated to participate in Physical Education classes. In light of this, the following study aims to analyze the reasons which lead some students to practice physical activities and sports outside of school, despite not showing motivation in Physical Education at school. Characterized as a qualitative case study, of a descriptive nature, seven students from a high school located in the countryside of Rio Grande do Sul State took part. The criteria for inclusion were the following: high level of absenteeism from the classes; confirmation of the low motivation to take part in the Physical Education classes; and the practicing of sports and physical activities outside of school. The data was collected by means of a semi-structured interview. The results showed that the students seek outside of school those physical activities and sports programs which bring them pleasure, personal satisfaction and learning which, despite seeking it, they do not find in their Physical Education classes at

Conexões: revista da Faculdade de Educação Física da UNICAMP, Campinas, v. 10, n. 2, p. 121-144, maio/ago. 2012.121 ISSN: 1983-9030
\end{abstract}


school.

Key-Words: Physical Education at school; High school; Motivation; Physical and sporting activities.

\title{
RELACIONES ENTRE LA PRÁCTICA DE ACTIVIDADES FÍSICAS Y DEPORTIVAS DE LOS ESTUDIANTES DE SECUNDARIA DENTRO Y FUERA DE LA ESCUELA
}

\begin{abstract}
RESUMEN
La literatura muestra que muchos estudiantes de secundaria no se sienten motivados a participar en clases de educación física. Por lo tanto, este estudio trata de analizar las razones que llevan a algunos estudiantes a la práctica de actividades físicas y deportivas fuera de la escuela, aunque no haya motivación en las clases de educación física en la escuela. Participaron de este estudio de caso cualitativo descriptivo siete estudiantes de una escuela secundaria privada del interior de la República de Rio Grande do Sul. Los criterios de inclusión fueron: alto número de faltas a clases, la confirmación de la baja motivación para participar en clases de educación física, y practicar actividades físicas y deportivas extraescolares. Los datos fueron recolectados a través de entrevista semi-estructurada. Los resultados mostraron que los estudiantes buscan fuera de la escuela aquellas actividades físicas y deportivas que les dan el placer, la satisfacción personal y el aprendizaje que, a pesar de buscar, no encuentran en clases de educación física escolar.
\end{abstract}

Palabras-Clave: Educación Física; Escuela secundaria; Motivación; Actividades físicas y deportivas. 


\section{INTRODUÇÃO}

O objeto de estudo da Educação Física é integrado por diferentes expressões e manifestações do movimento humano, exemplificadas por meio do jogo, do esporte, da ginástica, da dança e da luta. Nesse contexto, a prática pedagógica dos professores desempenha o papel fundamental de estimular o desenvolvimento das potencialidades físicas, motoras, cognitivas, afetivas, comunicacionais e psíquicas dos alunos. ${ }^{1,2}$ Essas diferentes expressões e manifestações têm por objetivo levar os alunos ao estabelecimento de relações e à construção de interpretações, que possibilitem ampliar seu esclarecimento e sua compreensão a respeito dos sentidos pessoais atribuídos à sua realidade de vida, às suas concepções e ao seu mundo. ${ }^{3,4,5}$

Diversos estudos têm destacado que as aulas de Educação Física devem contemplar conteúdos que sejam planejados e implementados pelos professores de forma crítica, criativa e objetiva, a fim de proporcionar aos alunos prazer, motivação, interesse e identificação com os temas tratados em aula. ${ }^{6,7,8}$ Segundo Magill, ${ }^{9}$ a relação entre aprendizagem e motivação é recíproca: um aluno pode aprender em consequência de sua motivação ou se motivar a partir da possibilidade de aprender mais. Conhecer quais motivos levam os alunos à prática de atividades motoras na escola pode contribuir no processo de ensino e aprendizagem, já que a aprendizagem e a motivação são processos interdependentes do homem. ${ }^{7}$

Outros estudos ${ }^{1,2,4,8,10,11,12,13,14,15}$ corroboram essas questões ao evidenciar que a não consideração dos fatores motivacionais nas aulas de Educação Física contribui para que os alunos não deem importância à prática corporal nas atividades físicas e esportivas durante as aulas e não vejam sentido na sua realização.

Dessa forma, o que se tem observado na literatura consultada ${ }^{10,16,17,18,19,20,21,22}$ é que interpretações dessa natureza, ao mesmo tempo em que têm afastado os alunos dos espaços escolares, os têm levado a buscar, em locais extraescolares, como clubes e academias, experiências que lhes tragam a satisfação, o prazer e o aprendizado que procuram na escola.

Conexões: revista da Faculdade de Educação Física da UNICAMP, Campinas, v. 10, n. 2, p. 121-144, maio/ago. 2012.121 ISSN: 1983-9030 
É nesse cenário que se insere o presente estudo, que foi concebido com o objetivo de identificar os motivos pelos quais alguns alunos do Ensino Médio, apesar de não sentirem motivação nas aulas de Educação Física, procuram atividades físicas e esportivas extraescolares.

\section{DECISÕES METODOLÓGICAS}

Para alcançar os objetivos estabelecidos nesta investigação, optou-se pela realização de um estudo de caso qualitativo, descritivo e de corte transversal. ${ }^{23,24}$

O grupo de participantes foi composto por sete estudantes do gênero feminino, regularmente matriculadas no Ensino Médio de uma escola particular de uma cidade do interior do Rio Grande do Sul. Todas as estudantes não sentiam motivação para participar das aulas de Educação Física, mas praticavam atividades físicas e esportivas fora da escola.

Os critérios de inclusão foram: ter elevado número de faltas (quatro ou mais no trimestre anterior à realização da pesquisa); ser caracterizado, pelo professor de Educação Física, como pouco participativo e/ou desmotivado; confirmar que realmente não sente motivação nas aulas de Educação Física; e ser praticante de atividades físicas e esportivas extraescolares (mais de duas vezes por semana, em seções com duração igual ou superior a 45 minutos). Foi a adoção desses critérios que levou à formação do grupo com sete estudantes, que vieram a participar da investigação.

Para a coleta de informações utilizou-se uma entrevista semiestruturada, elaborada, com base na literatura consultada, especificamente para esta investigação. As 20 perguntas abertas que compunham a entrevista instigavam as participantes à reflexão sobre as eventuais causas da desmotivação nas aulas de Educação Física, e faziam referência às razões que as levaram a optar pela prática de atividades físicas e esportivas fora da escola, bem como às características dessas atividades.

As transcrições textuais das entrevistas - avalizadas pelas participantes - tiveram seus fragmentos relativos aos fatores motivacionais e desmotivacionais identificados, analisados quanto ao seu teor e classificados em três categorias de análise, emergidas das próprias

Conexões: revista da Faculdade de Educação Física da UNICAMP, Campinas, v. 10, n. 2, p. 121-144, maio/ago. 2012.122 ISSN: 1983-9030 
informações coletadas e apoiadas na literatura consultada, quais sejam: (1) atividades escolares e extraescolares realizadas pelas estudantes; (2) seus objetivos com a realização de atividades físicas e esportivas extraescolares; e (3) os conteúdos abordados e as estratégias pedagógicas implementadas por seus professores nas aulas de Educação Física.

Para analisar as informações, optou-se, inicialmente, pelo estabelecimento de um paralelo entre as informações disponibilizadas pelas sete estudantes em cada uma das três categorias de análise, sendo essas categorias analisadas separadamente. Posteriormente, foi traçado um novo paralelo entre as resultados das três categorias de análise, buscando-se eventuais relações de causalidade ou de complementaridade entre elas.

O projeto de pesquisa foi aprovado pelo Comitê de Ética em Pesquisa com Seres Humanos (registro $n^{0}$ 395/2010). A Direção da escola na qual as estudantes cursavam o Ensino Médio, bem como seus professores de Educação Física e seus pais ou responsáveis, autorizaram a realização da investigação por meio da assinatura do Termo de Consentimento Livre e Esclarecido. As próprias estudantes, participantes da investigação, também assinaram esse Termo, concordando explicitamente em participar voluntariamente e em disponibilizar suas informações para publicação.

\section{ANÁLISE E DISCUSSÃO}

Nos últimos anos, diferentes estudos ${ }^{1,4,8,10,11,12,13,14,15,25}$ têm analisado as concepções dos alunos a respeito das aulas de Educação Física na escola, cujos resultados demonstram que grande parte deles não gosta das atividades propostas. Como consequência natural, os alunos são levados a não participar das aulas, indo buscar fora da escola (em clubes ou academias) atividades físicas e esportivas que lhes tragam satisfação e aprendizado.

Ao analisar as informações coletadas nesta investigação, relativas às questões que motivam e não as alunas à frequentarem as aulas de Educação Física, os temas que emergiram com mais força diziam respeito a: atividades escolares e extraescolares realizadas por elas, seus objetivos com a realização de atividades físicas e esportivas, a sequência de conteúdos abordados e as estratégias pedagógicas implementadas por seus professores nas aulas de Educação Física.

Conexões: revista da Faculdade de Educação Física da UNICAMP, Campinas, v. 10, n. 2, p. 121-144, maio/ago. 2012.123 ISSN: 1983-9030 
De acordo com as participantes da pesquisa, a motivação nas aulas de Educação Física surgiria por meio de atividades diferenciadas, que fugissem das quatro modalidades mais conhecidas e praticadas na escola, nomeadamente, o handebol, o basquete, o futebol e o voleibol.

Estudo realizado por Barros et al. $^{25}$ corrobora essa questão ao observar que tais modalidades são as mais praticadas na escola por adolescentes, tanto do gênero masculino quanto do gênero feminino. $\mathrm{O}$ mesmo autor descobriu em seu estudo que nas aulas de Educação Física, os alunos do Ensino Médio estão dispostos a novas experiências corporais, que lhes tragam um conhecimento maior com relação à cultura corporal de movimento.

Esta informação da literatura condiz com o que uma das alunas investigadas manifesta, relatando que esses esportes mais conhecidos não passam de "joguinhos normais". Para ela, jogos diferentes como golfe, tênis ou esportes adaptados a deficientes físicos, por exemplo, podem ter uma finalidade diferente do que as encontradas nas modalidades tradicionais.

Para outra participante do estudo, foi-lhe indagado se a sua desmotivação poderia ter sido originada pelo fato de ela já ter estudado demais essas modalidades durante o período escolar. Segundo ela, ter que estudar outra vez esses esportes não a atrai mais, "porque antes tínhamos trabalhos sobre regras de jogos e, depois, ainda tínhamos que jogar o jogo. Então, isso já me cansou".

Sentimentos dessa natureza podem ser explicados por estarem essas modalidades cada vez mais sistematizadas e regulamentadas, implicando na perda de uma parte das características lúdicas e educacionais do esporte.

Essa é uma demonstração de que, para o professor, não basta somente conhecer bem sobre os esportes mais tradicionais, mas sim, buscar conhecer e se especializar em atividades diferentes que ampliem o seu conhecimento e a sua competência como profissional da área

Conexões: revista da Faculdade de Educação Física da UNICAMP, Campinas, v. 10, n. 2, p. 121-144, maio/ago. 2012.124 ISSN: 1983-9030 
do movimento humano.

Correia $^{26}$ descobriu em seu estudo que, professores de escolas particulares entendem que a Educação Física deveria compreender os seguintes conhecimentos: consciência crítica do esporte, respeito pelas diferenças, aspectos de saúde, qualidade de vida, vivências motoras diferenciadas, atividades que promovam a autonomia do aluno, dança, luta, ginástica, entre outras. Esse viés também é contemplado nos $\mathrm{PCNs},{ }^{20}$ e percebe-se que os professores sabem quais são os conhecimentos que podem construir com seus alunos, mas há uma falta de preparo, apoio e inspiração para criar e para diferenciar as aulas no Ensino Médio.

Em discussão acerca dessa questão, Correia, ${ }^{26}$ observou que: há um desgaste maior do professor no sentido de providenciar recursos materiais e teóricos, diante da necessidade de coordenar diferentes programações de atividades em diferentes turmas; as próprias limitações de formação profissional do professor; e dificuldades em encontrar subsídios teóricos para desenvolver discussões sobre as implicações do movimento humano.

Segundo Soares et al., ${ }^{2}$ um dos entraves para a identificação de maiores mudanças na abordagem das aulas de Educação Física pode ser o fato de os próprios professores demonstrarem resistência a novas dinâmicas, parecendo que a forma tradicional e tecnicista ainda é a maneira mais fácil e eficiente de ensinar.

O Lições do Rio Grande ${ }^{27-a}$ sugere, por exemplo, que aprender a cobrir os espaços vazios no seu lado da quadra, durante o saque adversário no voleibol é um tipo de saber que permite desenvolver a competência de usar essa prática esportiva de forma proficiente e autônoma em atividades recreativas no contexto de lazer. Esta poderia ser uma forma de contextualização do conhecimento por parte do aluno, visto que praticaria a modalidade não somente com a intenção de reproduzir seus movimentos característicos, mas sim, a fim de conhecer sobre a importância da mesma em situação extraescolar.

Esse tipo de saber, segundo os mesmos referenciais, ${ }^{27}$ faz parte do tema esporte e, sendo esse um conhecimento que deve ser ensinado na escola, merece tratamento diferenciado.

\footnotetext{
${ }^{a}$ Referencial Curricular para escolas estaduais. Secretaria de Educação do Estado do Rio Grande do Sul. Conexões: revista da Faculdade de Educação Física da UNICAMP, Campinas, v. 10, n. 2, p. 121-144, maio/ago. 2012.125 ISSN: 1983-9030
} 
Muitas vezes, o fazer corporal em aula se resume à execução de movimentos sem pretensão de investimento em nível de apropriação que permita aos alunos praticar, fora da escola, à modalidade estudada.

Outro forte indício dessa oposição a mudanças pode ser explicado pelo fato de o professor ter uma maior identificação com algum esporte, trabalhando o ano todo somente a modalidade de sua preferência, deixando de lado outros tipos de expressão corporal importantes na vida do aluno. ${ }^{3}$ Em alguns casos, a natural identificação com conteúdos de maior domínio, em detrimento de todos os demais necessários de serem abordados nas aulas de Educação Física, é agravada pela estrutura dos programas de formação inicial dos professores, uma vez que, em determinadas realidades, temas de interesse dos jovens, como musculação e dança, figuram como disciplinas optativas.

Além disso, segundo as alunas participantes do estudo, os objetivos e os benefícios de praticar esportes não são claramente apresentados nas aulas. Consciência crítica acerca do esporte, esportes e mídia, vivências motoras diversificadas, técnicas de diferentes modalidades esportivas são conteúdos reivindicados pelas participantes do estudo, e que podem ser utilizados pelos professores e contribuir para a formação crítica dos alunos.

Nessa linha, Bracht ${ }^{28}$ ressalta que o esporte é um fenômeno polissêmico, com vários sentidos/significados sociais, que estabelecem uma mediação entre o aluno e seu aprender, no sentido de construir, demonstrar, compreender e explicar para poder intervir na realidade social complexa em que vive.

É necessário, pois, que os conhecimentos transmitidos por meio dos esportes tenham, por parte dos professores, um tratamento no sentido da cultura corporal de movimento, a partir de saberes que permitam desenvolver a competência em usar, de forma proficiente e autônoma, atividades recreativas no contexto de lazer, e não somente pela reprodução de movimentos sem sentido, jogando apenas por jogar. ${ }^{27}$

Outro fator que contribui para que os alunos não se identifiquem com os esportes é o de não existir uma sequência didática, lógica, na construção dos conhecimentos relacionados

Conexões: revista da Faculdade de Educação Física da UNICAMP, Campinas, v. 10, n. 2, p. 121-144, maio/ago. 2012.126 ISSN: 1983-9030 
a tais conteúdos. ${ }^{13}$ Para o autor, os alunos estudam quase sempre os mesmos conteúdos, por isso não percebem uma evolução com relação ao seu aprendizado, a não ser relativamente ao aprendizado meramente técnico.

Conforme destaca Gonçalves, ${ }^{5: 27}$ as aulas de Educação Física não fogem das características gerais das outras disciplinas, em relação ao controle do corpo, já que, além de não constituírem "momentos de autênticas experiências de movimento, que expressam a totalidade do ser humano, [...] desenrolam-se com o objetivo primordial de disciplinar o corpo". Nesses casos, alguns dos objetivos das aulas de Educação Física são alcançados, mas, por meio da "realização de movimentos repetitivos, isolados, sem sentido para o aluno, dissociados de afetos e lembranças, presos a padrões e transmitidos por comando pelo professor". 5:36

As aulas de Educação Física, segundo as alunas investigadas, não são fruto de um planejamento de conteúdos para cada série, pois, alguns temas que foram estudados no Ensino Fundamental continuam sendo vistos no Ensino Médio. A maioria das participantes do estudo não sente motivação nas aulas de Educação Física depois que ingressam no Ensino Médio, o que demonstra que os conteúdos já não atraem mais os alunos, por serem os mesmos que já vêm sendo contemplados durante anos na escola.

Para Krebs, ${ }^{13}$ a Educação Física perdeu seu contexto pedagógico e não existe uma verticalização dos conteúdos que respeite os níveis de desenvolvimento humano. O aluno aprende sempre os mesmos conteúdos desde a $5^{\text {a }}$ série do Ensino Fundamental até o terceiro ano do Ensino Médio. O mesmo autor defende que os conteúdos devem avançar numa complexidade sempre crescente no decorrer das séries, tanto do ponto de vista estritamente motor, quanto do ponto de vista cognitivo. Ao ingressar no Ensino Médio, os alunos já têm experiências motoras, adquiridas em etapas anteriores e a partir da vivência de conteúdos abordados até então.

Darido $^{29}$ acrescenta que tais conhecimentos podem ser desenvolvidos de forma que o tratamento contextualizado dos conteúdos propicie aos alunos uma aprendizagem significativa, pois estabelece uma relação de reciprocidade entre eles e o conteúdo. É

Conexões: revista da Faculdade de Educação Física da UNICAMP, Campinas, v. 10, n. 2, p. 121-144, maio/ago. 2012.127 ISSN: 1983-9030 
possível, ainda, associar essa contextualização com experiências cotidianas e conhecimentos adquiridos espontaneamente, fazendo com que o aluno deixe a condição de espectador e passe a intervir criticamente em situações construídas a partir do seu próprio aprendizado. Atitudes como essa permitirão aos alunos desenvolverem clareza e espírito crítico, descobrirem-se a si mesmos e assumirem seus compromissos diante da realidade que os cerca.

Nahas ${ }^{30}$ e Andrade e Antunes Neto ${ }^{31}$ sugerem que as atividades programadas para as aulas de Educação Física no Ensino Médio objetivem a educação para um estilo de vida ativo, ensinando aos alunos conceitos básicos da relação existente, por exemplo, entre atividade física, aptidão física e saúde, além de proporcionar vivências motoras lúdicas diversificadas.

Na opinião de Darido $^{29}$ não apenas a escolha de conteúdo e os objetivos são importantes, pois a atuação do professor também contribui significativamente para o contentamento dos alunos quando participam das aulas de Educação Física. Betti ${ }^{11}$ comprovou em sua pesquisa a importância do professor nessas questões, posto que foi apontado pelos alunos como sendo o principal responsável por gostarem ou não da disciplina de Educação Física.

Trazer para a aula o que os alunos gostam de praticar pode ser um dos objetivos iniciais na profissão de um professor, pois isso despertará no aluno a motivação necessária para que deixe de somente reproduzir movimentos sem intenção e crie um objetivo relacionado com a sua aprendizagem. O professor pode, ainda, experimentar novos conteúdos, novas estratégias, outras rotinas pedagógicas, que busquem devolver a autonomia e a valorização da disciplina de Educação Física na escola.

Matos e Neira ${ }^{32: 97}$ reportam-se a essa estratégia explicando que,

os planos de aula deveriam ser elaborados com a participação dos alunos, para conhecermos também as expectativas dos alunos dentro das atividades a serem trabalhadas, já que, muitas vezes, não se pensa na especificidade dos grupos durante as aulas.

Exemplo semelhante foi citado por uma das participantes do presente estudo, quando expôs, como sugestão, que o aluno deve "ter a chance de dar opiniões para o

Conexões: revista da Faculdade de Educação Física da UNICAMP, Campinas, v. 10, n. 2, p. 121-144, maio/ago. 2012.128 ISSN: 1983-9030 
professor a respeito da aula, desta maneira, traria para a aula atividades que deixariam os alunos mais motivados em participar". Essa atitude, adotada pelo professor, tem potencial para aumentar a valorização da Educação Física por parte dos alunos, que reverteria positivamente tanto para o seu próprio aprendizado quanto para o alcance dos objetivos estabelecidos pelo professor.

Tratando de questões que envolvam somente o conteúdo de suas aulas, e não desperdiçando tempo com fatores relacionados a não participação dos alunos durante as aulas, Soares et al. ${ }^{2}$ explicam que o professor teria maior facilidade para desempenhar um papel que direcionasse e possibilitasse ações efetivas na realidade dos alunos.

Quando perguntada sobre a sua motivação em realizar aulas de Educação Física na escola, uma das participantes do estudo relatou que "depende a aula que o professor dá. Por exemplo, quando ele dá uma aula mais diversificada, como taekwondo ou basquete em cadeira de rodas me atrai. Uma coisa mais normal que a gente corre e fica lá transpirando, eu não acho legal". Estudos de Betti ${ }^{11}$ e Darido ${ }^{29}$ apontam nessa direção, ao considerar que temas relativos, por exemplo, à inclusão de pessoas com necessidades educacionais especiais podem ser de grande aproveitamento para a aprendizagem dos alunos se forem abordados de modo a despertar nos alunos, entre outros, os sensos de justiça, igualdade e cidadania. As aulas de Educação Física, além de se constituírem em momentos de fruição corporal, podem se configurar num momento de reflexão sobre o corpo, a ética, a estética e as relações inter e intrapessoais.

Para algumas participantes da pesquisa, atividades de fitness, como jump e ginástica, também são modalidades que as atraem e, por isso, seriam fáceis de trabalhar com os alunos na escola. Outra estratégia que pode ser utilizada pelo professor, segundo as alunas, é trabalhar atividades que a turma domine bem, com o professor valendo-se da experiência prévia dos alunos para contextualizar o seu conhecimento sobre os assuntos. Para Darido et al., ${ }^{4}$ trazer para as aulas questões que envolvam aspectos relacionados ao cotidiano dos alunos poderia ser uma forma de associar os conteúdos, potencializando sua motivação e, consequentemente, seu aprendizado.

Conexões: revista da Faculdade de Educação Física da UNICAMP, Campinas, v. 10, n. 2, p. 121-144, maio/ago. 2012.129 ISSN: 1983-9030 
Desse modo, constatou-se que as alunas investigadas gostariam que o professor proporcionasse a prática da musculação e a da dança nas aulas de Educação Física. Segundo elas, esse tipo de atividade motivaria mais os alunos, visto que praticariam uma modalidade que gostam de realizar fora da escola.

De Ávila ${ }^{33}$ sugere a implementação de uma proposta de atividades rítmicas e expressivas para alunas do curso de Magistério, em nível médio. Interessante é observar que alunas do seu estudo, que antes não participavam das aulas, passaram a realizá-las, com o argumento de que agora não precisam jogar bola (em referência aos esportes coletivos) e de que não necessitam competir e ser melhor que ninguém (em referência à competição típica nos esportes), pois, assim podem realizar atividades que as atraem e lhes proporcionam aprendizado.

Posicionamentos semelhantes foram observados em estudo realizado por Fiorin, ${ }^{7}$ quando constatou que, apesar de os alunos ainda vincularem Educação Física com a prática esportiva, eles passaram a considerar outras práticas corporais durante as aulas.

Nesses exemplos, fica evidenciado que existe espaço para a inserção de outros conteúdos nas aulas de Educação Física no Ensino Médio, para além do basquetebol, do voleibol, do futebol e do handebol, principalmente quando o aluno já experimentou, no Ensino Fundamental, diferentes modalidades, tendo condições de optar por aquilo que lhe dá prazer e conhecimento.

A Educação Física é uma disciplina na qual o professor pode tratar de questões diferenciadas ou de questões já conhecidas, mas com estratégias diferentes, instigando o aluno e buscando sua motivação. Utilizar de contextos subjetivos é um componente a mais que a Educação Física tem com relação a outras disciplinas, como cooperação, solidariedade, liberdade e igualdade. ${ }^{5}$

É possível associar a Educação Física a outras questões contextualizadas da vida cotidiana ou com conhecimentos adquiridos espontaneamente, por meio de assuntos pertinentes à situação em que se encontram os alunos. Isso pode ser identificado nas proposições de Darido e Rangel, ${ }^{34: 78}$ quando lembram que

Conexões: revista da Faculdade de Educação Física da UNICAMP, Campinas, v. 10, n. 2, p. 121-144, maio/ago. 2012.130 ISSN: 1983-9030 
são preocupações comuns na vida dos jovens, a aparência, a sexualidade e a reprodução, hábitos de alimentação, limites das capacidades físicas, papel do esporte, repouso, atividade e lazer, padrões de beleza e saúde corporal e outros temas.

Estratégias que demonstrem aos alunos a importância e o benefício da Educação Física em sua vida, valorizando "a expressão do corpo que relaciona o homem com a realidade natural e social para que o aluno compreenda, reflita e critique o que passou e o que ele vive, e busque entender o mundo, transformando a realidade", 35:626

Atividades sempre iguais, nas quais os alunos não encontram prazer e satisfação em realizá-las, têm potencial para atrasar o aprendizado. Alunos de Ensino Médio necessitam estudar assuntos que utilizarão quando saírem da escola, para levarem consigo atitudes cidadãs e críticas, aproximando-os cada vez mais da realidade. ${ }^{20}$

Em suma, o fato de terem que vencer os desafios impostos por outras disciplinas, que são tradicionalmente caracterizadas como mais rígidas, de maior exigência, algumas alunas participantes do estudo são da opinião de que a Educação Física não necessita ser assim. Essa opinião, de que a disciplina de Educação Física não carece de maior grau de exigência, pode se originar na dificuldade das estudantes de identificar os objetivos que devem ser por elas alcançados durante as aulas. Em alguns casos, foram encontradas interpretações das aulas de Educação Física como tempo livre, como um direito concedido pelos professores após o cumprimento de todas as suas obrigações com as demais disciplinas.

Os resultados do estudo realizado por Darido ${ }^{29}$ mostram que há, de fato, um progressivo afastamento dos alunos da Educação Física na escola. Os $\mathrm{PCNs}^{20}$ também referem que há, nessa fase, uma visível evasão dos alunos das aulas, o que é um fator indesejável para todos os profissionais envolvidos, salientando, mais uma vez, o empobrecimento do trabalho do professor de Educação Física. Nessa esteira, algumas estudantes entrevistadas declararam ser "preferível praticar atividades físicas fora da escola do que na escola".

Paiano $^{36}$ conclui que o fato de a grande maioria dos alunos preferir atividades alternativas,

Conexões: revista da Faculdade de Educação Física da UNICAMP, Campinas, v. 10, n. 2, p. 121-144, maio/ago. 2012.131 ISSN: 1983-9030 
fora da escola, aponta para dois motivos: o primeiro é o não atendimento, por parte da escola, dos gostos e interesses dos alunos por meio dos esportes mais conhecidos, como: futebol, basquete, voleibol e handebol. O segundo motivo é distanciar-se de relacionamentos indesejados, pois, fora da escola, buscam-se outras amizades.

Todas as estudantes entrevistadas disseram praticar musculação fora da escola, tendo em comum, também, o fato de pagarem mensalidade no local em que praticam a modalidade. Isso pode ser relacionado ao que abordou Pereira, ${ }^{37}$ pois são estudantes de escolas particulares, tendo, portanto, maiores condições de pagar por uma atividade fora da escola. Alguns estudos sugerem que a decisão dos jovens, ao buscar a prática de atividades física e esportivas institucionalizadas fora do contexto escolar, pode ser influenciada por questões relacionadas ao poder aquisitivo dos alunos, às instituições privadas de ensino, uma vez que encontram maior facilidade para pagar uma academia ou uma escolinha esportiva privada. $^{38,39}$

Oliveira ${ }^{19}$ e Darido et al. $^{4}$ destacam algumas dificuldades de acesso a espaços físicos apropriados, como parques, praças e instalações esportivas, falta de segurança em determinadas circunstâncias para realizar atividade física ao ar livre e condições climáticas adversas como fatores principais na busca desses jovens por atividade física em locais especializados, ou seja, que ofereçam atividade física de forma comercial, como produto de consumo.

Quanto à frequência semanal, todas as estudantes praticam essas modalidades, em turno contrário ao escolar, de duas a cinco vezes por semana e durante um mínimo de uma hora por sessão, o que sugere a dedicação de um tempo muito maior do que aquele requerido pelas aulas de Educação Física.

As atividades que as estudantes investigadas praticam foram por elas eleitas com base em diferentes objetivos, como, por exemplo, por praticarem desde a infância - como a dança ou por vislumbrarem o corpo ideal, magro, "firme" - como a musculação. Isso demonstra que os professores podem utilizar como estratégia de motivação a predisposição dos alunos em realizar algumas atividades e alcançar objetivos predeterminados.

Conexões: revista da Faculdade de Educação Física da UNICAMP, Campinas, v. 10, n. 2, p. 121-144, maio/ago. 2012.132 ISSN: 1983-9030 
Um dos objetivos ao realizar a musculação fora da escola, e que prevaleceu nas respostas das estudantes entrevistadas, foi o estético. Elas querem ficar mais magras, umas porque dizem comer demais, outras porque desejam ficar com o corpo mais firme, o que demonstra uma preocupação com questões estéticas, talvez influenciadas pelo estereotipo corporal imposto pela mídia, qual seja o de um corpo mais delineado e firme, que transpareça saúde e qualidade de vida. ${ }^{40,41,42}$

A questão estética pode estar relacionada, também, à exigência do grupo de amigos que as estudantes têm, pois, muitas vezes para serem aceitas e/ou reconhecidas, necessitam adequar-se a padrões visuais, de modo a serem respeitadas e valorizadas por terem um corpo bonito e aparência marcante. De estudo feito por Barros ${ }^{43}$ destacou-se que grande parte dos adolescentes começa a praticar musculação justamente para se destacar no grupo de amigos. Observou-se, também, no estudo de Silva ${ }^{44}$, que dificilmente um adolescente se matricula sozinho em uma academia, geralmente vai acompanhado de um amigo ou de parte do grupo.

A crença de que podem alterar sua forma corporal motiva os jovens à prática da musculação. No entanto, as transformações, muitas vezes, poderão acontecer de maneira imperceptível para esses adolescentes. Sendo assim, e conforme conclui Carvalho ${ }^{45}$, esses jovens devem ser orientados em relação aos padrões de corpo e beleza estabelecidos pela mídia, revelando-os os prós e os contras de seguir certos padrões, estabelecidos por outras culturas, além da exploração comercial do corpo, que transforma o supérfluo em essencial.

O objetivo das estudantes de chegar à forma física ideal também indica que o professor pode valer-se dessa motivação estética e transferi-la para o campo da saúde e abordar nas aulas questões relativas, por exemplo, à prevenção de doenças, à alimentação e ao limite das capacidades físicas durante o treinamento. Ou seja, que esses temas desenvolvam ainda mais o conhecimento das estudantes, fazendo com que a prática da atividade extraescolar seja realizada como um propósito a mais na vida das estudantes, efetivamente relacionado à saúde e à qualidade de vida. Apesar disso, o estudo realizado por Assatirri e Daólio ${ }^{40}$ demonstrou que os professores de Educação Física, mesmo reconhecendo a importância da

Conexões: revista da Faculdade de Educação Física da UNICAMP, Campinas, v. 10, n. 2, p. 121-144, maio/ago. 2012.133 ISSN: 1983-9030 
abordagem desses temas nas suas aulas, sentem não ter a formação necessária para isso.

Outra ocorrência marcante encontrada nas respostas das estudantes pesquisadas foi o fato de todas buscarem essa prática por incentivo próprio. Por não existir qualquer tipo de obrigação ou imposição para a prática da modalidade, a pré-disposição das estudantes e os seus objetivos podem ser utilizados como ponto de partida para o planejamento dos conteúdos e das estratégias do professor de Educação Física para suas aulas.

Outra modalidade praticada fora da escola por duas estudantes participantes do estudo foi a dança, mas com um objetivo distinto da musculação. Segundo as estudantes, o objetivo maior em realizar aulas de dança é o bem-estar. Esse é outro fator que pode contribuir com o professor de Educação Física na elaboração de suas aulas, uma vez que "a dança é uma atividade que, por meio de movimentos corporais, traduz pensamentos e sentimentos, que nesta idade, necessitam ser libertados para que o conhecimento corporal seja ampliado". 46:26

A dança é uma das atividades a ser inserida no contexto escolar ${ }^{20}$, pois muito se sabe acerca das virtudes e dos benefícios que ela traz à vida dos alunos, sendo utilizada como uma forma de expressão e de manifestação corporal diferenciada das demais experienciadas pelos alunos na maior parte da vida, desenvolvendo, assim, seu repertório motor. $^{47,48}$ Para Nanni ${ }^{46: 27}$, a dança na escola retrata as ansiedades, as necessidades, as ideias e os interesses dos alunos, "aliado à forte necessidade que o ser humano tem de extrapolar a sua essência ou transcender a sua existência em evasões positivas e significativas em todas as circunstâncias de sua vida".

Dessa maneira, podem ser levados em conta também os tipos de dança realizados em cada local do País e do mundo, por exemplo, o que contextualiza o conhecimento a partir da integração da Educação Física com outras áreas do conhecimento, criando uma interdependência das disciplinas entre si. ${ }^{21,36,49}$

Para além dos aspectos já elencados, o que também colabora com a motivação das alunas participantes do estudo no exercício de atividades como musculação e dança fora da escola

Conexões: revista da Faculdade de Educação Física da UNICAMP, Campinas, v. 10, n. 2, p. 121-144, maio/ago. 2012.134 ISSN: 1983-9030 
é o fato de essas atividades serem desenvolvidas individualmente e sem caráter de competição. Isso as deixa mais livres e com a consciência de que, como declarou uma das participantes da pesquisa: "não preciso ganhar de ninguém, e estou somente com pessoas que eu gosto".

Esses exemplos concordam com os achados dos estudos de Betti ${ }^{11}$ para quem os colegas representam fator decisivo na motivação dos alunos durante as aulas de Educação Física no primeiro ano do Ensino Médio.

Para uma das entrevistadas, uma "forte amizade pode se romper por causa de uma aula aonde exista competição". De acordo com ela, "o fato de ter os times pode ser bom, mas não de ter que ganhar do colega e do amigo que estão sempre juntos no mesmo time, fora da escola".

$\mathrm{Na}$ visão dessas alunas, a aula de Educação Física não deve ter objetivos competitivos, pois, dessa maneira, não existe aprendizagem, mas discórdia entre eles, visto que os alunos deixam para trás questões importantes no aproveitamento do ensino, para se preocuparem em ganhar do colega, seja qual for o custo, querendo demonstrar que jogam melhor do que outras, criando conflitos que levam a brigas, desencontros e frustrações.

Paiano $^{36}$ encontrou resultados semelhantes em sua pesquisa sobre a modalidade esportiva que os alunos gostavam mais, sendo escolhidas pela grande maioria dos adolescentes aquelas atividades onde existe menor contato físico e menor competição durante as aulas.

Na visão das entrevistadas, o que desmotiva os alunos nas aulas de Educação Física é a postura irredutível de alguns colegas mais habilidosos que não abrem espaço para que os menos habilidosos joguem também. Percebe-se, aqui, um hiato a ser preenchido pela presença do professor, ao lançar mão de estratégias que deem a todos as mesmas oportunidades.

Essas atitudes por parte dos colegas, segundo as alunas investigadas, levam-nas a não ter incentivo para participar, pois sabem que os mais habilidosos é que "vão levar a melhor". Isso demonstra não ser o aprendizado o foco principal das aulas vividas pelos alunos, mas

Conexões: revista da Faculdade de Educação Física da UNICAMP, Campinas, v. 10, n. 2, p. 121-144, maio/ago. 2012.135 ISSN: 1983-9030 
apenas jogos sem objetivo de ensinar ou de construir algum valor que elas poderão levar para suas vidas.

Segundo os $\mathrm{PCNs}^{20}$, a falta de interesse origina-se, na maioria das vezes, no desconhecimento, sendo o professor o responsável pela aproximação do educando aos novos conhecimentos, que contribuam com sua formação.

Essa ocorrência pode estar relacionada à existência da espontaneidade e à despreocupação que são peculiares à prática de tais modalidades, pois, nos esportes já conhecidos, as alunas pesquisadas se sentem inferiorizadas diante dos colegas, visto que eles levam a atividade a sério e elas não.

Dessa maneira, acredita-se que exista forte vinculação entre o que motiva as alunas pesquisadas, o que elas praticam fora da escola, e o que gostariam de fazer nas aulas de Educação Física escolar.

\section{CONSIDERAÇÕES FINAIS}

O presente estudo procurou identificar quais são as razões pelas quais alguns alunos do Ensino Médio de escolas particulares, apesar de não sentirem motivação nas aulas de Educação Física, procuram atividades físicas e esportivas extracurriculares.

Mediante os resultados encontrados, pode-se inferir que os motivos mais indicados pelas participantes do estudo para procurarem atividades físicas e esportivas extraescolares foram: as modalidades propostas pelos professores serem sempre as mesmas, desde o Ensino Fundamental, nomeadamente o futebol, o basquete, o voleibol e o handebol; não conseguirem discernir os conteúdos propostos para cada série; e a falta de dinamicidade nas estratégias metodológicas utilizadas pelos professores.

Durante o estudo, diversas foram as propostas sugeridas pelas participantes, sobre como poderiam ser as aulas de Educação Física. Segundo elas, as aulas necessitam oportunizar atividades diferenciadas, assuntos contextualizados e objetivos diversificados, buscando atender às necessidades dos alunos do Ensino Médio, e às demandas dessa faixa etária.

Conexões: revista da Faculdade de Educação Física da UNICAMP, Campinas, v. 10, n. 2, p. 121-144, maio/ago. 2012.136 ISSN: 1983-9030 
Em decorrência da desmotivação nas aulas de Educação Física por parte das alunas, foi constatado que elas buscam fora da escola atividades físicas e esportivas que lhes tragam prazer, satisfação e aprendizado ao realizá-las. Desse modo, se verificou que as alunas gostariam que o professor proporcionasse a prática da musculação e da dança nas aulas de Educação Física, pois, segundo elas, essas atividades motivariam mais os alunos, visto que praticariam modalidades pelas quais se interessam, têm afinidade e costumam realizar fora da escola.

Isso demonstra que os professores podem utilizar essas motivações das alunas para planejar e implementar tais atividades em suas aulas, de modo que se construam os conhecimentos necessários para os alunos do nível médio de ensino.

Ficou evidenciado, também, por meio dos momentos de reflexão, que o aluno do Ensino Médio é crítico e contestador e busca uma educação com qualidade. Tem interesse no sentido de que haja uma educação melhor, diferenciada e com acompanhamento de um professor qualificado e motivado.

Nessa perspectiva, espera-se que o professor busque estratégias metodológicas que motivem os alunos do Ensino Médio, contribuindo com o engajamento de toda a turma nas aulas de Educação Física, configurando-se em um interessante ponto de partida para professores interessados em enriquecer a sua prática pedagógica.

\section{REFERÊNCIAS}

${ }^{1}$ FREIRE, J. B.; SCAGLIA, A. J. Educação como prática corporal. São Paulo: Scipione, 2003.

${ }^{2}$ SOARES, C. L. et al. Metodologia do ensino de Educação Física. São Paulo: Cortez, 1992.

${ }^{3}$ BONONE, C. G.; MOLINA NETO, V. A prática da Educação Física na escola privada

Conexões: revista da Faculdade de Educação Física da UNICAMP, Campinas, v. 10, n. 2, p. 121-144, maio/ago. 2012.137 ISSN: 1983-9030 
de Ensino Médio em Caxias do Sul - RS: perspectiva do professor, 2000. $199 \mathrm{f}$. Dissertação (Mestrado em Educação Física) - Universidade Federal do Rio Grande do Sul, Caxias do Sul, 2000.

${ }^{4}$ DARIDO, S. C. et al. Educação Física, a formação do cidadão e os Parâmetros Curriculares Nacionais. Revista Paulista de Educação Física, São Paulo, v. 15, n. 1, p. 17-32, 2001. Disponível em:

$<$ http://citrus.uspnet.usp.br/eef/uploads/arquivo/v15\%20n1\%20artigo2.pdf $>$. Acesso em: 10 out. 2010.

${ }^{5}$ GONÇALVES, M. F. C. Educação escolar: identidade e diversidade. Florianópolis: Insular, 2003.

${ }^{6}$ ALMEIDA, C. de A.; CAUDURO, M. T. O desinteresse pela Educação Física no Ensino Médio. Revista Digital, Buenos Aires, v. 17, n. 106, p. 1-8, 2007. Disponível em: $<$ http://www.efdeportes.com/efd106/o-desinteresse-pela-educacao-fisica-no-ensino-

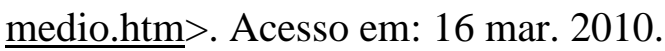

${ }^{7}$ FIORIN, G. S. Uma proposta para além do esporte na educação física escolar: as expectativas e a avaliação dos alunos. 1997. 224 f. Monografia (Especialização) -Instituto de Biociências, Universidade Estadual Paulista, Rio Claro, 1997.

${ }^{8}$ SANTIN, S. Educação Física: uma abordagem filosófica da corporeidade. Ijuí: Ed. da Unijuí, 1987.

${ }^{9}$ MAGILL, R. A. Aprendizagem motora: conceitos e aplicações. São Paulo: Blücher, 1984.

${ }^{10}$ BETTI, M. Educação física e sociedade. São Paulo: Movimento, 1991.

${ }^{11}$ BETTI, I. C. R. O prazer em aulas de Educação Física escolar: a perspectiva discente, 1992. 189 f. Dissertação (Mestrado em Educação Física) - Unicamp, Campinas, 1992.

Conexões: revista da Faculdade de Educação Física da UNICAMP, Campinas, v. 10, n. 2, p. 121-144, maio/ago. 2012.138 ISSN: 1983-9030 
${ }^{12}$ ECCHELI, S. D. A motivação como prevenção da indisciplina. Educar em Revista, Curitiba, v. 10, n. 32, p. 1-9, 2008. Disponível em:

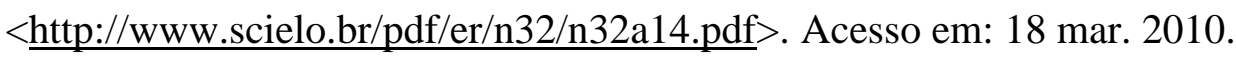

${ }^{13}$ KREBS, R. J. Teoria dos sistemas ecológicos. Santa Maria: Ed. da UFSM, 1997.

${ }^{14}$ STRAZZACAPPA, M. A educação e a fábrica de corpos: a dança na escola. Cadernos CEDES, Campinas, v. 21, n. 53, p. 69-83, 2001.

${ }^{15}$ TAPIA, J. A.; FITA, E. C. A motivação em sala de aula: o que é e como se faz. São Paulo. Loyola, 1999.

${ }^{16}$ DARIDO, S. C. et al. Educação Física no Ensino Médio: reflexões e ações. Motriz: revista de Educação Física da UNESP, Rio Claro, v. 5, n. 2, p. 138-145, 1999. Disponível em: 〈http://www.rc.unesp.br/ib/efisica/motriz/05n2/5n202Darido.pdf $>$. Acesso em: 6 mar. 2010 .

${ }^{17}$ IVANOWICZ, B. A imagem e a consciência do corpo. In: BRUNHS. H. T. (Org.). Conversando sobre o corpo. São Paulo: Papirus, 1994. p. 63-81.

${ }^{18}$ MARTINELLI, C. R. et al. A Educação Física no Ensino Médio: motivos que levam as alunas a não gostarem de participar das aulas. Revista Mackenzie de Educação Física e Esporte, São Paulo, v. 5, n. 2, p. 13-19, 2006. Disponível em:

<http://www3.mackenzie.br/editora/index.php/remef/article/view/1288/993 >. Acesso em: 6 mar. 2006.

${ }^{19}$ OLIVEIRA, J. A. Níveis de prática de atividade física habitual em adolescentes. Revista Brasileira de Medicina do Esporte, Niterói, v. 7, n. 6, p. 187-199, 2001.

${ }^{20}$ BRASIL. Ministério da Educação. Secretaria de Educação Média e Tecnológica. Parâmetros Curriculares Nacionais: ensino médio. Brasília: Ministério da Educação,

Conexões: revista da Faculdade de Educação Física da UNICAMP, Campinas, v. 10, n. 2, p. 121-144, maio/ago. 2012.139 ISSN: 1983-9030 
1999.

${ }^{21}$ PEREIRA, F. M. Ensino Médio, Educação Física e conhecimento. Revista Paulista de Educação Física, São Paulo, v. 14, n. 1, p. 32-54, 2000. Disponível em: $<$ http://citrus.uspnet.usp.br/eef/uploads/arquivo/v14\%20n1\%20artigo3.pdf $>$. Acesso em: 28 mar. 2010.

${ }^{22}$ TOIGO, A. M. Níveis de atividade física na Educação Física escolar e durante o tempo livre em crianças e adolescentes. Revista Mackenzie de Educação Física e Esporte, São Paulo, v. 6, n. 1, p. 45-56, 2007. Disponível em: < http://www3.mackenzie.br/editora/index.php/remef/article/view/1282/986>. Acesso em: 16 mar. 2010.

${ }^{23}$ DENZIN, N. K.; LINCOLN, Y. S. O planejamento da pesquisa qualitativa: teorias e abordagens. 2. ed. Porto Alegre: Artmed, 2006.

${ }^{24}$ YIN, R. K. Estudo de caso: planejamento e métodos. 4. ed. Porto Alegre: Bookman, 2010.

${ }^{25}$ BARROS, R. et al. O uso do tempo livre por adolescentes de uma comunidade metropolitana no Brasil. Revista Adolescência Latinoamericana, Porto Alegre, v. 3, n. 2, p. 10-15, 2002. Disponível em: <http://ral-adolec.bvs.br/scielo.php?script=sci arttext\&pid=S1414-71302002000200008\&lng=es\&nrm=iso>. Acesso em: 12 maio 2010.

${ }^{26}$ CORREIA, W. R. Planejamento participativo e o ensino da Educação Física no $2^{\circ}$ grau. Revista Paulista de Educação Física, São Paulo, n. 2, p. 43-48, 1996. Disponível em: $<$ http://citrus.uspnet.usp.br/eef/uploads/arquivo/v10\%20supl2\%20artigo8.pdf $>$ Acesso em: 16 mar. 2010.

${ }^{27}$ RIO GRANDE DO SUL. Secretaria da Educação. Lições do Rio Grande: Ensino Fundamental e Ensino Médio, 2009. Disponível em: http://www.educacao.rs.gov.br/dados/refer_curric_vol2.pdf. Acesso em: 10 out. 2010.

Conexões: revista da Faculdade de Educação Física da UNICAMP, Campinas, v. 10, n. 2, p. 121-144, maio/ago. $2012 .{ }^{140}$ ISSN: 1983-9030 
${ }^{28}$ BRACHT, V. Educação Física escolar e o programa de esporte na escola: possibilidades legitimadoras de um componente curricular. In: CONGRESSO DE EDUCAÇÃO FÍSICA E CIÊNCIAS DO ESPORTE, 1., 2002, Santa Tereza. Anais... Vitória: Secretaria Estadual do Colégio Brasileiro de Ciências do Esporte, 2002.

${ }^{29}$ DARIDO, S. C. A Educação Física na escola e o processo de formação dos não praticantes de atividade física. Revista Brasileira de Educação Física e Esporte. São Paulo, v. 18, n. 1, p. 61-80, jan./mar. 2004. Disponível em:

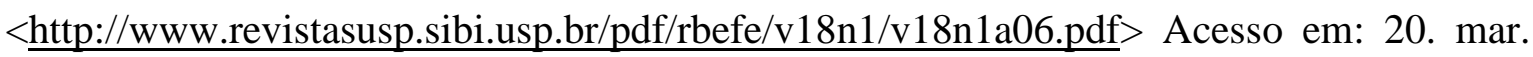
2010.

${ }^{30}$ NAHAS, M. V. Educação Física no Ensino Médio: educação para um estilo de vida ativo no terceiro milênio. In: SEMINÁRIO DE EDUCAÇÃO FísICA ESCOLAR/ ESCOLA DE EDUCAÇÃO FÍSICA E ESPORTE, 4., 1997, São Paulo. Anais... São Paulo, 1997.

${ }^{31}$ ANDRADE, R. C. B.; ANTUNES NETO, J. As aulas de Educação Física no Ensino Médio: Implicações nas discussões sobre as temáticas aprendizagem e qualidade de vida. Conexões: Revista da Faculdade de Educação Física da UNICAMP, Campinas, v. 6, n. especial, p. 389-396, jul. 2008. Disponível em:

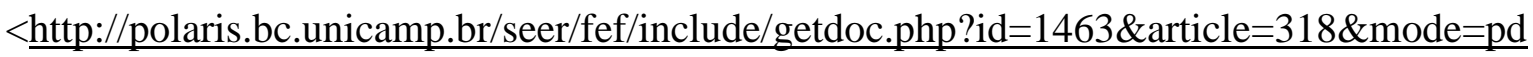
f>. Acesso em: 5 dez. 2011.

${ }^{32}$ MATOS, M. G.; NEIRA, M. G. Educação Física na adolescência: construindo o conhecimento na escola. São Paulo: Phorte, 2000.

${ }^{33}$ DE ÁVILA, A. C. V. Para além do esporte: a expressão corporal nas aulas de Educação Física no segundo grau. 1995. Monografia (Graduação em Educação Física) - Instituto de Biociências, Universidade Estadual Paulista, Rio Claro, 1995.

${ }^{34}$ DARIDO, S. C.; RANGEL, I. C. A. Educação Física na escola: implicações para a prática pedagógica. Rio de Janeiro: Guanabara Koogan, 2005.

Conexões: revista da Faculdade de Educação Física da UNICAMP, Campinas, v. 10, n. 2, p. 121-144, maio/ago. $2012 .{ }^{141}$ ISSN: 1983-9030 
${ }^{35}$ MIRANDA, A. C. M.; LARA, L. M.; RINALDI, I. P. B. A Educação Física no Ensino Médio: saberes necessários sob a ótica docente. Motriz: revista de educação física da UNESP, Rio Claro, v. 15, n. 3, p. 621-630, 2009. Disponível em: <http://www.periodicos.rc.biblioteca.unesp.br/index.php/motriz/article/view/2948/2499>. Acesso em: 17 jul. 2010.

${ }^{36}$ PAIANO, R. Possibilidades de orientação da prática pedagógica do professor de Educação Física: situações de desprazer na opinião dos alunos. Revista Mackenzie de Educação Física e Esporte, São Paulo, v. 18, n. 1, p. 47-57, 2006. Disponível em: <http://www3.mackenzie.com.br/editora/index.php/remef/article/viewFile/1301/1005>. Acesso em: 12 mar. 2010.

${ }^{37}$ PEREIRA, F. M. O cotidiano escolar e a Educação Física necessária. Pelotas: Ed. da UFPel, 1997.

${ }^{38}$ PERFEITO, R. B. et al. Avaliação das aulas de Educação Física na percepção dos alunos de escolas públicas e particulares. Revista da Educação Física/UEM, Maringá, v. 19, n. 4, p. 489-499, 2008. Disponível em:

<http://periodicos.uem.br/ojs/index.php/RevEducFis/article/viewArticle/6009>.

Acesso em: 28 mar. 2010.

${ }^{39}$ ZULIANI, L. R. Educação Física escolar: uma proposta de diretrizes pedagógicas. Revista Mackenzie de Educação Física e Esporte, São Paulo, v. 1, n. 1, p. 73-81, 2002. Disponível em:

〈http://www3.mackenzie.br/editora/index.php/remef/article/view/1363/1065>. Acesso em: 10 out. 2010.

${ }^{40}$ ASSATIRRI, D. S.; DAÓLIO, J. A intervenção do professor de Educação Física junto a aluno do Ensino Médio sobre o fenômeno do culto ao corpo. Conexões: revista da Faculdade de Educação Física da UNICAMP, Campinas, v. 9, n. 1, p. 67-91, jan./abr. 2011. Disponível em:

$<$ http://polaris.bc.unicamp.br/seer/fef/include/getdoc.php?id=1989\&article=604\&mode=pd

Conexões: revista da Faculdade de Educação Física da UNICAMP, Campinas, v. 10, n. 2, p. 121-144, maio/ago. $2012 .{ }^{142}$ ISSN: 1983-9030 
f>. Acesso em: 5 dez. 2011.

${ }^{41}$ FERREIRA, M. E. C.; CASTRO, A. P. A.; GOMES, G. A obsessão masculina pelo corpo: malhado, forte, sarado. Revista Brasileira de Ciências do Esporte, Campinas, v. 27, n. 1, p. 167-182, 2005. Disponível em:

<http://www.rbceonline.org.br/revista/index.php/RBCE/article/view/141/150>. Acesso em: 20 mar. 2010.

${ }^{42}$ MUUSS, R. Teorias da adolescência. Belo Horizonte: Interlivros, 1974.

${ }^{43}$ BARROS, J. Treinamento contra resistido na adolescência. Revista Corpus et Scientia, São Paulo, v. 5, n. 2, p. 18-25, 2009. Disponível em:

$\langle$ http://www.unisuam.edu.br/corpus/pdf/2009Volume5N2/Artigo_2.pdf $>$. Acesso em: 12 set. 2010.

${ }^{44}$ SILVA, P. Esteróides anabolizantes no esporte. Revista Brasileira de Medicina do Esporte, Niterói, v. 8, n. 1, p. 235-243, 2002.

${ }^{45}$ CARVALHO, Y. M. O “mito” da atividade física e saúde. São Paulo: Hucitec, 2001.

${ }^{46}$ NANNI, D. Dança educação: da pré-escola à universidade. 4. ed. Rio de Janeiro: Sprint, 2003.

${ }^{47}$ DANTAS, M. Perspectivas sobre a construção de corpos dançantes. In: SEMINÁRIO NACIONAL DE ARTE E EDUCAÇÃO, 18., 2004, Montenegro: Anais... Porto Alegre, 2004.

${ }^{48}$ PAVlOVA, A. De peito aberto para debater e pensar a dança. O Globo. Rio de Janeiro, 2 jul. 2001.

${ }^{49}$ CHICATI, K. C. Motivação nas aulas de Educação Física no Ensino Médio. Revista da Educação Física/UEM, Maringá, v. 11, n. 1, p. 97-105, 2000. Disponível em:

Conexões: revista da Faculdade de Educação Física da UNICAMP, Campinas, v. 10, n. 2, p. 121-144, maio/ago. 2012.143 ISSN: 1983-9030 
<http://periodicos.uem.br/ojs/index.php/RevEducFis/article/view/3799/2611>. Acesso em: 18 mar. 2010.

Recebido em: 06 dezembro 2012. Aceito em: 09 abril 2012.

Conexões: revista da Faculdade de Educação Física da UNICAMP, Campinas, v. 10, n. 2, p. 121-144, maio/ago. 2012.144 ISSN: 1983-9030 